\title{
Prognostic implications of PIK3CA amplification in curatively resected liposarcoma
}

\author{
Joo Hoon Kim ${ }^{1, *}$, Jae Seok Lee ${ }^{2, *}$, Eo Jin Kim², Kyu Hyun Park ${ }^{3}$, Ki Hyang Kim, \\ Seong Yoon $\mathrm{Yi}^{5}$, Han Seong Kim${ }^{6}$, Yong Jin Cho ${ }^{7}$, Kyoo-Ho Shin ${ }^{7}$, Joong Bae Ahn ${ }^{1}$, \\ Hyuk Hu ${ }^{8}$, Kyung Sik Kim ${ }^{8}$, Young Deuk Choi ${ }^{9}$, Sunghoon Kim ${ }^{10}$, Young Han Lee ${ }^{11}$, \\ Jin-Suck Suh ${ }^{11}$, Sung Hoon Noh ${ }^{8}$, Sun Young Rha ${ }^{1}$, Hyo Song Kim ${ }^{1}$ \\ ${ }^{1}$ Division of Medical Oncology, Department of Internal Medicine, Yonsei Cancer Center, Yonsei University College of Medicine, \\ Seoul, Korea \\ ${ }^{2}$ Department of Pathology, Dongguk University College of Medicine, Dongguk University Ilsan Hospital, Goyang, Korea \\ ${ }^{3}$ Cancer Metastasis Research Center, Song Dang Institute for Cancer Research, Yonsei University College of Medicine, \\ Seoul, Korea \\ ${ }^{4}$ Department of Internal Medicine, Busan Paik Hospital, Inje University College of Medicine, Busan, Korea \\ ${ }^{5}$ Department of Internal Medicine, Ilsan Paik Hospital, Inje University College of Medicine, Ilsan, Korea \\ ${ }^{6}$ Department of Pathology, Ilsan Paik Hospital, Inje University College of Medicine, Ilsan, Korea \\ ${ }^{7}$ Department of Orthopedic Surgery, Yonsei University College of Medicine, Seoul, Korea \\ ${ }^{8}$ Department of Surgery, Yonsei University College of Medicine, Seoul, Korea \\ ${ }^{9}$ Department of Urology, Yonsei University College of Medicine, Seoul, Korea \\ ${ }^{10}$ Department of Obstetrics and Gynecology, Yonsei University College of Medicine, Seoul, Korea \\ ${ }^{11}$ Department of Radiology, Yonsei University College of Medicine, Seoul, Korea \\ *These authors have contributed equally to this work \\ Correspondence to: Sun Young Rha, e-mail: rha7655@yuhs.ac \\ Hyo Song Kim, e-mail: hyosong77@yuhs.ac
}

Keywords: liposarcoma, PIK3CA, amplification, mutation

Received: January 05, $2016 \quad$ Accepted: March 02, $2016 \quad$ Published: March 21, 2016

\section{ABSTRACT}

Background: We investigated the epidemiologic characteristics and prognostic significance of PIK3CA mutations/amplifications in curative resected liposarcoma.

Patients and methods: A total of 125 liposarcoma tissue samples were collected over a 12-year period. PIK3CA mutations and gene copy number amplifications were analyzed by pyrosequencing and fluorescence in situ hybridization (FISH).

Results: Nine of the 105 liposarcomas (8.6\%) had activating PIK3CA mutation. PIK3CA mutations were more frequent in myxoid/round cell and pleomorphic tumors compared with well-differentiated/dedifferentiated tumors $(13.3 \%$ vs. $2.2 \%$, $P=0.043$ ). In FISH PIK3CA analysis, copy number gain was detected in 14 of the 101 tumors (13.9\%): $11(10.9 \%)$ tumors had increased gene copy number (polysomy) and $3(3.0 \%)$ exhibited gene amplification. In survival analysis, patients with PIK3CA copy number gain had a worse prognosis compared to patients without PIK3CA amplification (median disease-free survival [DFS] 22.2 vs. 107.6 months $p=0.005$ ). By multivariate analysis, PIK3CA copy number gain was an independent prognostic factor for worse DFS ( $P=0.027$; hazard ratio, 2.400; 95\% confidence interval 1.105 to 5.213). PIK3CA mutation was not associated with DFS and overall survival.

Conclusions: We demonstrated PIK3CA mutation and amplification in liposarcoma. PIK3CA copy number gain was an independent poor prognostic factor for DFS. Further studies are needed to evaluate the potential diagnostic and therapeutic role of PIK3CA mutations and amplifications in liposarcoma. 


\section{INTRODUCTION}

Soft tissue sarcoma (STS) is a heterogeneous disease with over 50 histologic subtypes, with various biological behaviors and genetic features [1]. In adults, liposarcoma is the most common type STS, representing $17-25 \%$ of the total cases [2]. Although surgical resection is the primary treatment for localized disease, many liposarcomas eventually progress to advanced disease that is either unresectable, metastatic, or both. For patients with those tumors, the mortality is high, and local and/or systemic tumor burden also results in significant morbidity [3].

For prognostic reasons, liposarcoma is subdivided into 5 subtypes by the World Health Organization classification: well-differentiated, myxoid/round cell, dedifferentiated, pleomorphic, and mixed-type liposarcoma [4]. Well-differentiated and myxoid liposarcoma are low-grade tumors, while dedifferentiated, round cell, and pleomorphic liposarcoma are high-grade tumors. Low-grade tumors have a low frequency of metastasis, and high-grade tumors often manifest with clinically aggressive behavior and distant metastasis. Besides the recognition of specific histologic subtypes, better understanding of distinct genetic and molecular aberrations is critical for therapeutic strategy.

The phosphatidylinositol-3-kinase (PI3K)-AktmTOR signaling pathway plays a central role in regulating tumor cell metabolism and survival [5]. Activation of the PI3K pathway occurs upon engagement with mutated or amplified phosphatidylinositol-4,5-bisphosphate 3-Kinase, catalytic subunit Alpha (PIK3CA) gene It increases p110 $\alpha$ expression, PI3K activation, and phosphorylation of downstream signaling molecules. Akt-PIK3CA gene amplification was found in $10-30 \%$ of non-small cell lung cancer, breast cancer, and colon cancer [6-8]. Activating somatic mutations were also identified in various solid tumors $[9,10]$. Recently, PIK3CA mutation was reported in $12 \%$ and $18 \%$ of myxoid/round-cell liposarcoma, and it was associated with Akt activation and poor clinical outcome [11, 12]. Despite accumulating evidence of biological role, there have been few studies reporting the frequency of PIK3CA aberration (including mutations and amplifications) for all liposarcoma subtypes.

In this study, we evaluated the frequency of PIK3CA amplification and mutation in surgically resected liposarcoma. Furthermore, we also determined the prognostic impact of PIK3CA genetic aberration for liposarcoma patients.

\section{RESULTS}

\section{Clinical and pathological features}

A total of Korean 125 patients with liposarcoma who underwent curative resection were analyzed. The clinical characteristics such as gender, age, primary tumor site, histology, and tumor size are presented in Table 1. The median age at diagnosis was 52 years (range: $18-84$ years), and male was predominant $(62.4 \%)$. The median tumor size was $14.1 \mathrm{~cm}$, and one-third of all tumors were over $15 \mathrm{~cm}$. Primary tumors mainly occurred in the extremities $(\mathrm{n}=61,48.8 \%)$, with the other sites being the retroperitoneum/intra-abdominal region $(\mathrm{n}=35,28.0 \%)$, inguinal area/genital organ ( $\mathrm{n}=10,8.0 \%)$, and other sites $(\mathrm{n}=19,15.2 \%)$. The distribution of histologic subtypes were as follows: myxoid in 52 patients $(41.6 \%)$, welldifferentiated in 45 patients (36.0\%), pleomorphic in 10 patients $(8.0 \%)$, dedifferentiated in 9 patients $(7.2 \%)$, and round cell in 9 patients $(7.2 \%)$.

\section{PIK3CA amplification}

Of the 125 cases, 101 tumor samples were evaluable for PIK3CA FISH analysis. Based on PIK3CA gene expression values, tumors were categorized into three groups: (I) normal copy number, tumors with $\leq 2$ copies per cell with a $P I K 3 C A / \mathrm{CEN} 3$ ratio $<2.0$; (II) polysomy, tumors with an average PIK3CA signal per nucleus $4.0 \geq$ to $>2.0$; and (III) amplification, tumors with $>4$ copies per cell and/or a PIK3CA/CEN3 ratio $\geq 2.0$. By these criteria, of the 101 cases, 14 tumors (13.9\%) demonstrated copy number gain, 11 (10.9\%) had polysomy, and $3(3.0 \%)$ had gene amplification (Table 2, Figure 1). The median PIK3CA gene copy numbers were 2.3 (range, 2.1-2.6) and 6.5 (range, 5.010.3 ) in PIK3CA the polysomy and amplification groups, respectively. We also analyzed the association between PIK3CA amplification status and clinical parameters. $P I K 3 C A$ copy number gain was significantly associated with older age and larger tumor size (Table $1, \mathrm{P}=0.023$ and $\mathrm{P}=0.040$, respectively). There were no significant differences in PIK3CA copy number change with respect to sex, histology, and primary tumor site.

With a median follow-up time of 50.6 months, the 5-year DFS and OS rates were $57.9 \%$ and $82.8 \%$, respectively. The PIK3CA copy number gain group (polysomy and amplification) had a significantly shorter DFS compared with that of normal group (Figure 2A, median 22.0 vs. 107.6 months, $\mathrm{P}=0.005$ ). Using the $\mathrm{Cox}$ proportional hazard model adjusted for gender, age, histology, and tumor location, PIK3CA copy number gain was an independent poor prognostic factor for DFS (Table 3, $\mathrm{P}=0.027$; hazard ratio [HR], 2.400; 95\% confidence interval [CI] 1.105 to 5.213). Older age $(\mathrm{p}=0.013 ; \mathrm{HR}, 2.393 ; 95 \%$ CI 1.203 to 4.760$)$ was also an independent poor prognostic factor for DFS. There was no significant difference in OS with respect to PIK3CA copy number gain $(\mathrm{P}=0.144$, Figure $2 \mathrm{~B})$

\section{PIK3CA mutation}

Among the 125 patients, 105 tumor samples were available for PIK3CA mutation analysis. Activating 
Table 1: Patient characteristics based on PIK3CA amplification

\begin{tabular}{|c|c|c|c|c|c|c|c|}
\hline \multirow[t]{2}{*}{ Characteristics } & \multicolumn{2}{|c|}{ All patients } & \multicolumn{2}{|c|}{$\begin{array}{c}\text { Copy number gain } \\
\text { (Polysomy + } \\
\text { Amplification)* }\end{array}$} & \multicolumn{2}{|c|}{ Normal copy number } & \multirow[t]{2}{*}{$\boldsymbol{P}^{\dagger}$} \\
\hline & No. & $\%$ & No. & $\%$ & No. & $\%$ & \\
\hline Number of patients & 125 & 100 & 14 & 13.9 & 87 & 86.1 & \\
\hline $\begin{array}{l}\text { Age, years } \\
\text { Median (range) }\end{array}$ & \multicolumn{2}{|c|}{$52(18-84)$} & \multicolumn{2}{|c|}{$61(37-84)$} & \multicolumn{2}{|c|}{$50(20-83)$} & 0.023 \\
\hline Gender & & & & & & & 0.487 \\
\hline Male & 78 & 62.4 & 8 & 57.1 & 58 & 66.7 & \\
\hline Female & 47 & 37.6 & 6 & 42.9 & 29 & 33.3 & \\
\hline $\begin{array}{l}\text { Tumor size, cm } \\
\text { Median (range) }\end{array}$ & \multicolumn{2}{|c|}{$14.1(1.0-37.0)$} & \multicolumn{2}{|c|}{$18.5(5.5-37.0)$} & \multicolumn{2}{|c|}{$12.25(1.0-31.0)$} & 0.040 \\
\hline $0-5 \mathrm{~cm}$ & 19 & 15.2 & 0 & 0 & 16 & 18.4 & \\
\hline $5-10 \mathrm{~cm}$ & 26 & 20.8 & 3 & 21.4 & 18 & 20.7 & \\
\hline $10-15 \mathrm{~cm}$ & 26 & 20.8 & 1 & 7.1 & 20 & 30.0 & \\
\hline$>15 \mathrm{~cm}$ & 46 & 36.8 & 8 & 57.1 & 28 & 32.2 & \\
\hline unknown & 8 & 6.4 & 2 & 14.3 & 5 & 5.7 & \\
\hline \multicolumn{3}{|l|}{ Histologic classification } & & & & & 0.063 \\
\hline Well- and De-differentiated & 54 & 43.2 & 9 & 64.3 & 33 & 37.9 & \\
\hline Well differentiated & 45 & 36.0 & 7 & 50.0 & 30 & 34.5 & \\
\hline Dedifferentiated & 9 & 7.2 & 2 & 14.3 & 3 & 3.4 & \\
\hline $\begin{array}{l}\text { Mixoid/Round cell, } \\
\text { Pleomorphic }\end{array}$ & 71 & 58.8 & 5 & 35.7 & 54 & 62.1 & \\
\hline Myxoid & 52 & 41.6 & 2 & 14.3 & 44 & 50.6 & \\
\hline Round cell & 9 & 7.2 & 1 & 7.1 & 5 & 5.7 & \\
\hline Pleomorphic & 10 & 8.0 & 2 & 14.3 & 5 & 5.7 & \\
\hline \multicolumn{3}{|l|}{ Primary tumor site } & & & & & 0.051 \\
\hline Extremity & 61 & 48.8 & 4 & 28.6 & 46 & 52.9 & \\
\hline Lower extremity & 55 & 44.0 & 4 & 28.6 & 43 & 49.4 & \\
\hline Upper extremity & 6 & 4.8 & 0 & 0 & 3 & 3.4 & \\
\hline $\begin{array}{l}\text { Retroperitoneum/ } \\
\text { intraabdomen }\end{array}$ & 35 & 28.0 & 8 & 57.1 & 18 & 20.7 & \\
\hline Retroperitoneum & 27 & 21.6 & 5 & 35.7 & 15 & 17.2 & \\
\hline Intraabdomen & 8 & 6.4 & 3 & 21.4 & 3 & 3.4 & \\
\hline Inguinal area $\&$ genital organ & 10 & 8.0 & 1 & 7.1 & 8 & 9.2 & \\
\hline Other area & 19 & 15.2 & 1 & 7.1 & 15 & 17.2 & \\
\hline $\begin{array}{l}\text { Time to recurrence, months } \\
\text { Median (range) }\end{array}$ & \multicolumn{2}{|c|}{$22.0(3.7-240.9)$} & \multicolumn{2}{|c|}{$13.8(6.2-95.2)$} & \multicolumn{2}{|c|}{$34.4(3.7-240.9)$} & \\
\hline
\end{tabular}

Abbreviations: PIK3CA, phosphatidylinositol-4,5-bisphosphate 3-Kinase, Catalytic Subunit Alpha;CEN3, centromere3 *PIK3CA amplification was defined as if one of the following criteria is fulfilled: (1) PIK3CA/CEN3 ratio is $\geq 2.0$, (2) average number of PIK3CA signal per nucleus $>4.0$

"PIK3CA polysomy were defined as average number of PIK3CA signal per nucleus $4.0 \geq$ to $>2.0$.

${ }^{\dagger} \chi^{2}$ test, Fisher's exact test, $t$-test or Mann-Whitney U test. 
Table 2: PIK3CA amplification status according to liposarcoma histologic subtype

\begin{tabular}{lcccc}
\hline Histologic classification & $\begin{array}{c}\text { Normal Copy } \\
\text { Number }\end{array}$ & Polysomy & Amplification & Total, $\mathbf{n}(\%)$ \\
\cline { 3 - 5 } & $\mathbf{3 3}$ & $\mathbf{6}$ & $\mathbf{3}$ & $\mathbf{9}(\mathbf{2 1 . 4})$ \\
Well- and De-differentiated & 30 & 6 & 3 & \\
Well- differentiated & 3 & 0 & 0 & $\mathbf{5}(\mathbf{8 . 5})$ \\
De-differentiated & $\mathbf{5 4}$ & $\mathbf{5}$ & 0 & \\
Myxoid/Round cell, Pleomorphic & 49 & 3 & 0 & \\
Myxoid/ Round cell & 5 & 2 & $\mathbf{3 ( 3 . 0 )}$ \\
Pleomorphic & $\mathbf{8 7}(\mathbf{8 6 . 1 )}$ & $\mathbf{1 1}(\mathbf{1 0 . 9 )}$ & $\mathbf{1 4}(\mathbf{1 3 . 9 )}$ \\
Total, $\mathbf{n}(\%)$ & \multicolumn{3}{c}{} \\
\hline
\end{tabular}

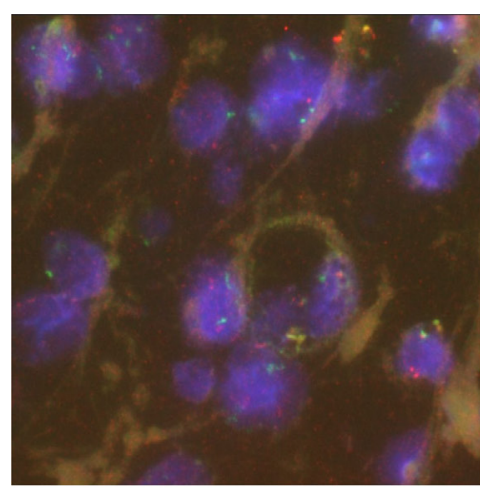

(A) normal

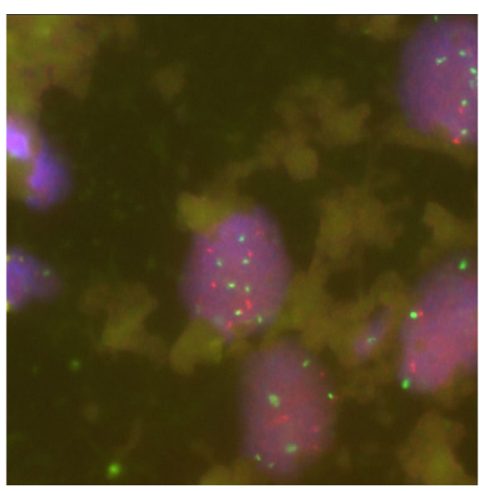

(B) polysomy

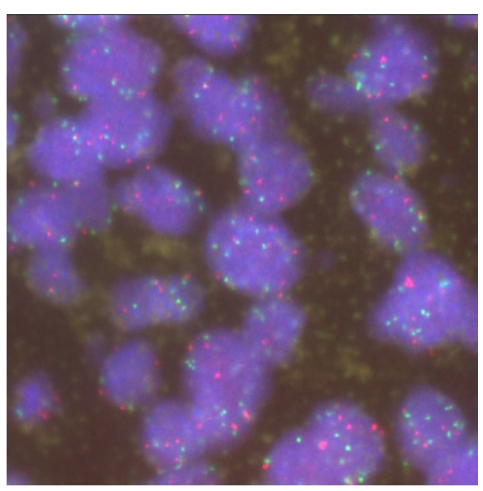

(C) amplification

Figure 1: Representative fluorescent in situ hybridization of tumors with A. normal copy numbers, B. polysomy, C. and PIK3CA amplification.

(A)

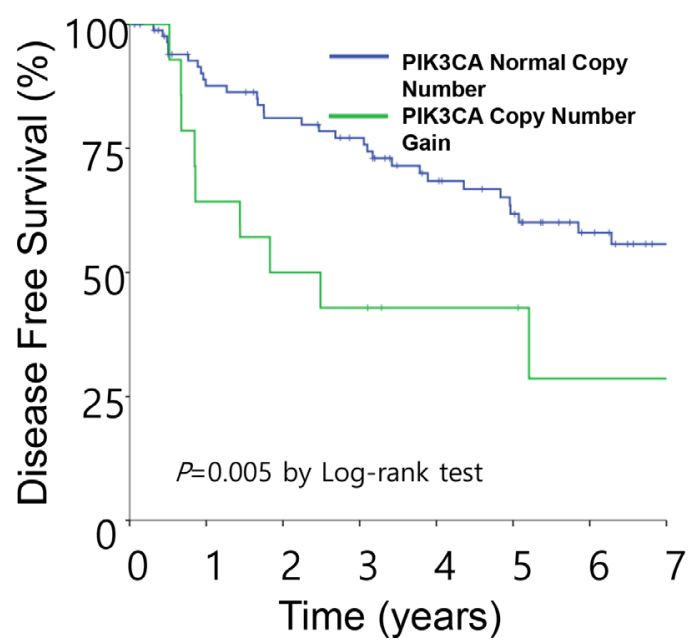

(B)

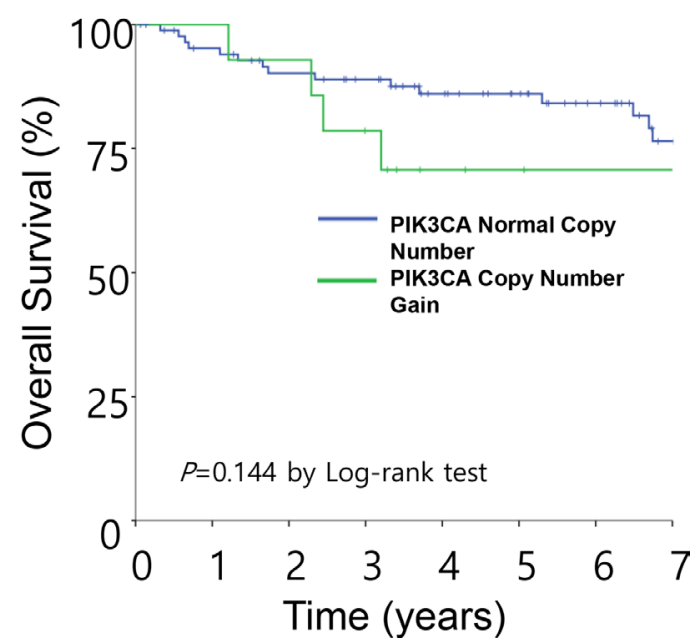

Figure 2: Survival analysis based on PIK3CA status. A. The median disease-free survival (DFS) was 22.0 months in patients with PIK3CA copy number gain and 107.6 months in the normal group. B. The median overall survival (OS) was not significantly different between the two groups. 
Table 3: Prognostic factors for disease-free survival and overall survival

\begin{tabular}{|c|c|c|c|c|c|c|c|}
\hline \multirow[t]{2}{*}{ Variable } & \multirow[t]{2}{*}{ Category } & \multicolumn{3}{|c|}{ DFS } & \multicolumn{3}{|c|}{ OS } \\
\hline & & HR & $95 \%$ CI & $P$ & HR & $95 \%$ CI & $P$ \\
\hline $\begin{array}{l}P I K 3 C A \text { copy } \\
\text { number status }\end{array}$ & $\begin{array}{c}\text { Copy number gain } v s \\
\text { Normal copy number } \\
\text { (ref) }\end{array}$ & 2.400 & $1.105-5.213$ & 0.027 & 1.628 & $0.555-4.770$ & 0.375 \\
\hline Age & $\begin{array}{c}\text { Age } \geq 52 \text { years } v s \\
\text { Age }<52 \text { years (ref) }\end{array}$ & 2.393 & $1.203-4.760$ & 0.013 & 3.875 & $1.351-11.118$ & 0.012 \\
\hline Gender & $\begin{array}{l}\text { Female } v s \\
\text { Male (ref) }\end{array}$ & 0.650 & $0.357-1.186$ & 0.161 & 1.078 & $0.431-2.697$ & 0.873 \\
\hline Histology & $\begin{array}{l}\text { Mixoid/Round cell, } \\
\text { Pleomorphic } v s \\
\text { Well/De-diff (ref) }\end{array}$ & 1.692 & $0.896-3.196$ & 0.105 & 1.336 & $0.538-3.316$ & 0.533 \\
\hline $\begin{array}{l}\text { Primary tumor } \\
\text { sites }\end{array}$ & $\begin{array}{l}\text { Extremity, Inguinal/ } \\
\text { genital, other area } \\
\text { vs Retroperitoneum/ } \\
\text { Intraabdomen (ref) }\end{array}$ & 0.880 & $0.439-1.762$ & 0.718 & 1.335 & $0.420-4.242$ & 0.624 \\
\hline
\end{tabular}

Abbreviations: DFS, disease-free survival; OS, overall survival; HR, hazard ratio; CI, confidence interval; ref, reference; diff, differentiated

PIK3CA mutation was detected in $9(8.6 \%)$ of 105 cases, with 5 cases of exon 9 mutation and 4 cases of exon 20 mutation (Table 4). For PIK3CA exon 9, E542K mutations were identified in 2 tumors, Q546K mutations were identified in 2 tumors, and an E545K mutation was identified in 1 tumor. For exon 20, H1047R mutations were identified in 3 tumors, and an $\mathrm{H} 1047 \mathrm{~L}$ was identified in 1 tumor (Figure 3). There was no co-occurrence of exon 9 and exon 20 mutations.

With respect to histologic subtype, PIK3CA mutations were more frequent in well-differentiated/ dedifferentiated tumors compared with myxoid/round cell/pleomorphic tumors (Table 4, 13.3\% vs. 2.2\%, $\mathrm{P}=0.043)$. Of all mutated tumors, 6 tumors $(66.7 \%)$ were myxoid/round cell, 2 tumors $(22.2 \%)$ were pleomorphic, and 1 tumor (11.1\%) was well-differentiated (Table 4, Supplementary Table 1). There were no statistically significant differences in PIK3CA mutation based on sex, age, tumor size, and primary tumor sites (Supplementary Table 1). We also performed analyses to examine the association between PIK3CA mutations and survival outcome. PIK3CA mutation was not associated with a significant difference in DFS or OS (data not shown, $\mathrm{p}=0.739$ and $\mathrm{p}=0.376$, respectively)

\section{Correlation between PIK3CA mutation and copy number status}

There were 82 cases with complete data on PIK3CA mutation and copy number status (Supplementary Table 2). Although not statistically significant, PIK3CA mutations were more frequent in the cases of copy number gain. Of the 7 tumors with PIK3CA mutation, 3 tumors $(21.4 \%)$ exhibited copy number gain, whereas only 4 tumors $(5.9 \%)$ had normal copy numbers.

\section{DISCUSSION}

We conducted this study to examine the frequency and prognostic impact of PIK3CA mutations and amplifications in patients with curatively resected liposarcoma. To our knowledge, this is the first study evaluating the prognostic impact of PIK3CA polysomy and amplification in a large cohort of Asian liposarcoma patients. We demonstrated that $P I K 3 C A$ aberration is a poor prognostic factor in liposarcoma.

Accumulating evidence has suggested different outcomes for the major histologic subtypes of liposarcoma. Therefore, histologic classification is known as a most strong prognostic factor for survival [13-16]. Among the 5 subtypes of liposarcoma, well-differentiated and myxoid liposarcoma had the most favorable prognoses, while dedifferentiated, round cell, and pleomorphic liposarcomas often manifest with clinically aggressive behavior and distant metastasis. Overall, with use of conventional doxorubicin-based chemotherapy, median survival remains less than 12 months for patients with metastatic/ unresectable tumors [17]. The limited improvement after conventional therapy treatment prompts us to explore the molecular biology and identify prognostic and druggable biomarkers. 
Table 4: PIK3CA mutational status according to liposarcoma histologic subtype

\begin{tabular}{|c|c|c|c|c|c|c|c|}
\hline \multirow{3}{*}{$\begin{array}{l}\text { Histologic } \\
\text { classification }\end{array}$} & \multirow[t]{3}{*}{ Wild type } & \multicolumn{6}{|c|}{ Mutation } \\
\hline & & \multicolumn{3}{|c|}{ Exon 9} & \multicolumn{2}{|c|}{ Exon 20} & \multirow[t]{2}{*}{ Total, n (\%) } \\
\hline & & E542K & E545K & Q546K & H1047R & H1047L & \\
\hline $\begin{array}{l}\text { Well- and De- } \\
\text { differentiated }\end{array}$ & 44 & 0 & 0 & 0 & 1 & 0 & $1(2.2)$ \\
\hline $\begin{array}{l}\text { Well- } \\
\text { differentiated }\end{array}$ & & & & & 1 & 0 & 1 \\
\hline De-differentiated & & & & & 0 & 0 & \\
\hline $\begin{array}{l}\text { Myxoid and Round } \\
\text { cell, Pleomorphic }\end{array}$ & 52 & 2 & 1 & 2 & 2 & 1 & $8(13.3)$ \\
\hline $\begin{array}{l}\text { Myxoid and } \\
\text { Round cell }\end{array}$ & 43 & 2 & 0 & 1 & 2 & 1 & 6 \\
\hline Pleomorphic & 9 & 0 & 1 & 1 & 0 & 0 & 2 \\
\hline Total, n (\%) & $96(91.4)$ & & $5(4.8)$ & $9(8.6)$ & & & $P=0.043$ \\
\hline
\end{tabular}

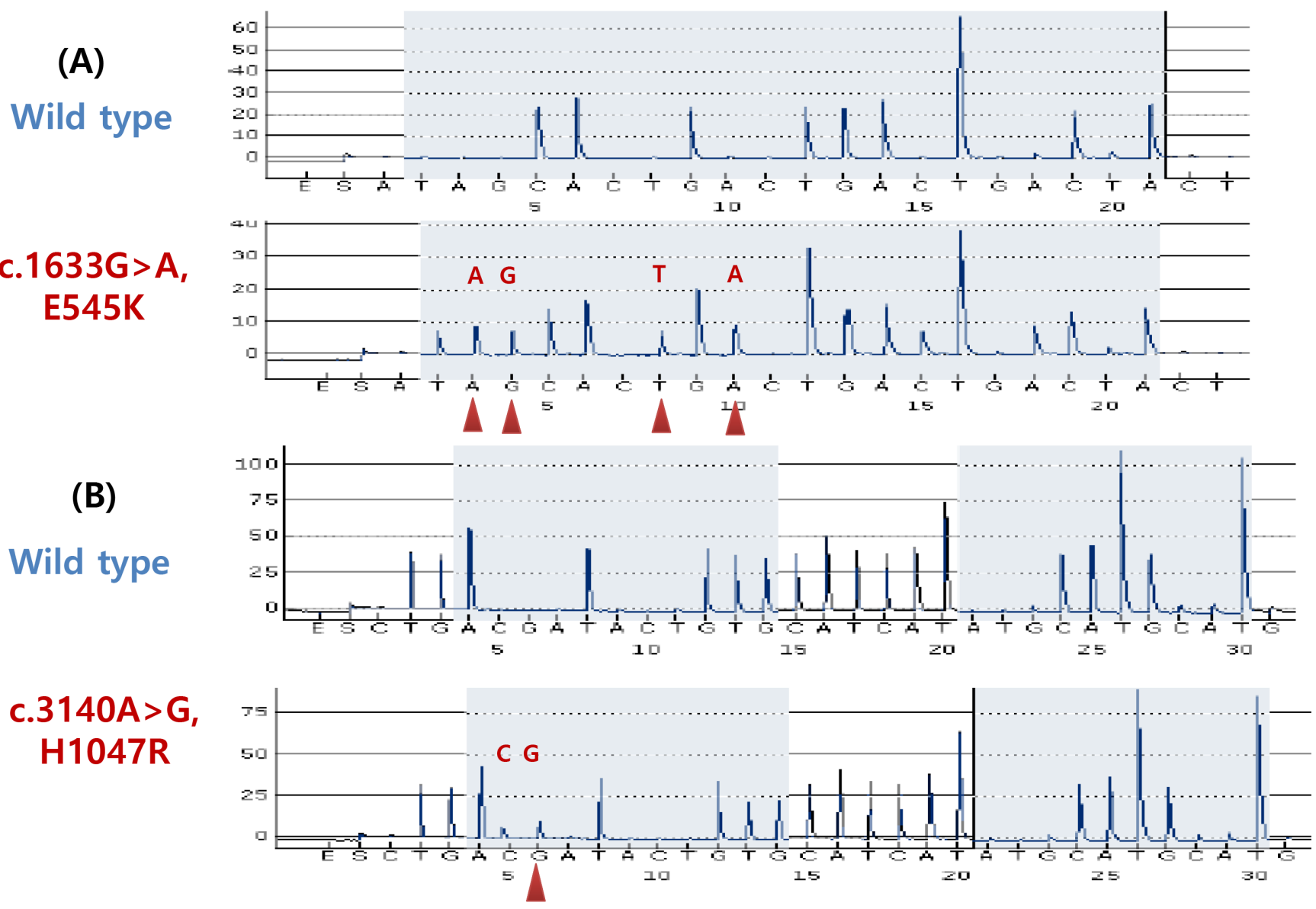

Figure 3: PIK3CA mutations in liposarcoma detected by pyrosequencing. A. Wild-type and exon 9 E545K (G1633A) mutations. B. Wild-type and exon $20 \mathrm{H} 1047 \mathrm{R}$ (A3140G) mutations. 
Despite known targeted therapeutic options in solid tumors (KIT or PDGFRA mutations in gastrointestinal stromal tumors), STS still lacks therapeutically relevant genetic alterations. Even knowledge of genetic alteration frequency is limited. A recent comprehensive genome study reported frequently mutated genes, including TP53, $N F 1$, and PIK3CA, in STS [11]. Among them, PIK3CA mutation was observed in $18 \%$ of myxoid/round cell liposarcomas. Therefore, $P I K 3 C A$ may be a putative driver gene in liposarcoma, with available therapeutic agents worthwhile.

Activation of the PI3K pathway, generally as result of PIK3CA amplification, has been demonstrated in $12 \%$ cases of lung cancer, $32 \%$ cases of head and neck cancer, and $24 \%$ cases of ovarian cancer [18-20]. Regarding the prognostic role of $P I K 3 C A$ amplification, the results have been controversial. In head and neck squamous cell carcinoma, PIK3CA amplification led to earlier recurrence [18]. For nasopharyngeal carcinoma, amplification was associated with distant metastasis, advanced stage, and poor OS [21]. On the other hand, amplification played no significant role in squamous cell lung cancer cohort [8]. Clinicopathologic heterogeneity, including primary tumor site, pathologic stage, and adjuvant treatment, may contribute to these controversial results. However, because of its rarity of sarcoma, no exact frequency of $P I K 3 C A$ amplification has been identified in sarcoma. Only The Cancer Genome Atlas (TCGA) data had reported 1\% frequency of $P I K 3 C A$ amplification and few comparable studies were reported with clinical cases. In our study, by carefully assessing a large cohort of liposarcoma cases, we were able to clarify the prognostic value of PIK3CA amplification in a homogenous patient population. PIK3CA amplification was significantly associated with poor DFS regardless of gender, age, histology, or tumor location, as an independent prognostic factor in curatively resected liposarcoma.

To evaluate $P I K 3 C A$ copy number gain, we used FISH. Previous studies defined PIK $3 C A / C E P 3 \geq 2[22-$ 24] as $P I K 3 C A$ amplification, and some studies used $P I K 3 C A>4[18,25]$. In our large cohort study, we used a combination of these criteria and demonstrated that amplification and polysomy have significant prognostic impacts on liposarcoma patients. FISH is an easy and useful method by which one can visualize individual cancer cells in routine clinical practice. Our criteria need further validation in future clinical trials with targeted agents.

Mutations in the PIK3CA gene are mostly located within hotspots in exons 9 and 20 and lead to PI3K pathway activation [26]. Regarding the prognostic significance of PIK3CA mutation, previous reports yielded controversial results $[6,26-29]$. PIK3CA mutation has been reported $14-18.3 \%$ of myxoid/roundcell liposarcoma and associated with shorter DFS with mass spectrometry-based genotyping $[11,12]$. Here, we report PIK3CA mutations in $8.6 \%$ of liposarcoma by employing a pyrosequencing approach and not associated with prognostic outcome. Although the majority of mutant tumors $(66.6 \%)$ were of the myxoid/round-cell subtype, additional mutant cases were also detected in well-differentiated, dedifferentiated, and pleomorphic liposarcoma. The limited sensitivity of sequencing method may result in low frequency or clinical outcome and further studies are warranted.

Despite first-line standard treatment with doxorubicin, median survival remains dismal. gemcitabine and docetaxel are frequently used as second-line treatment for STS [30]. While the total response rate for all patients is $16 \%$, only 2 out of 20 liposarcoma patients had stable disease at 6 months. Pazopanib was another potential breakthrough as a salvage treatment for STS [31]. However, pazopanib showed favorable efficacy in patients with leiomyosarcoma and synovial sarcoma, but not in adipocytic sarcoma [32]. Similar outcomes were observed in our Asian STS patients who received pazopanib treatment [33]. Therefore, exploration of therapeutically tractable target based on molecular biology is strongly warranted. Recently, local amplification of the 12q13-15 regions, which contain copies of $C D K 4$, was reported in well-differentiated liposarcoma [34]. However, because that subtype is relatively indolent and easily curable with surgical resection, CDK4 inhibitors are not necessary for treatment of well differentiated liposarcoma [16]. In our study, we found frequent aberrations of the PIK3CA gene mainly in the aggressive subtypes (round cell and pleomorphic), and it is worth considering as a therapeutic target.

PIK3CA amplification and/or mutation are associated with increased activity of the PI3K effector pAkt, suggesting that amplified or mutated tumors may be sensitive to PI3K inhibitors [22, 35]. In lung cancer cell lines, $37 \%$ of squamous cell harbored PIK3CA amplification and they were sensitive to PI3K inhibitor GDC-0941 with less than $1 \mu \mathrm{mol} / \mathrm{L}$ of IC50 [35]. In a preclinical platform from Cancer Cell Line Encyclopedia, PIK3CA-amplified tumors were sensitive to BYL719, a PI3K $\alpha$-selective inhibitor [36]. Cell lines with PIK3CA amplification was positively associated with BYL719 sensitivity $(\mathrm{P}=0.0037)$ and tumor-bearing mice with PIK3CA amplification responded to BYL719, leading to a response rate of $-18 \%$ (lung cancer) and $-80 \%$ (gastric cancer). Despite preliminary data, recent phase I trials have explored the potential predictive role of the $P I K 3 C A$ gene. In a phase I trial with GDC-0941, a heavily treated ovarian cancer patient with $P I K 3 C A$ amplification experienced disease stabilization for 4 months with significant pharmacodynamic changes [37]. While previous trials with PI3K inhibitors have been conducted in non-selected patients, recent clinical trials with PI3K inhibitors are ongoing for those with PIK3CA gene alterations (ClinicalTrials.gov number NCT01928459 
and NCT01608022). As shown in our study, liposarcoma may be a promising potential candidate for use of PI3K inhibitors. Further study with preclinical model is warranted to validate the therapeutic role in sarcoma.

Here, we report PIK3CA aberration as an independent poor prognostic factor for curatively resected liposarcoma. Our findings also indicate that PIK3CA inhibitor is a promising therapeutic target for liposarcoma.

\section{MATERIALS AND METHODS}

\section{Patients and tumor tissues}

This study was conducted in a cohort of patients with liposarcoma who underwent curative resection at Severance Hospital, Busan Paik Hospital, and Ilsan Paik Hospital. A total of 125 formalin-fixed, paraffin-embedded primary liposarcoma specimens were available for examination of PIK3CA aberrations. All diagnoses were reviewed by two experienced pathologists (LJS and HSK) in conjunction with immunohistochemical staining data. Only those cases of confirmed liposarcoma containing tissue adequate for analytic purposes were included. Liposarcoma was classified into 5 histologic subgroups based on Evans Classification [38]: well-differentiated, myxoid, dedifferentiated, round, and pleomorphic.

Patient information was collected by reviewing the medical records for evaluations of clinicopathologic characteristics and survival outcomes. Primary tumors were located in the extremity, retroperitoneum/intraabdominal region, inguinal area/genital organs, and other.

\section{PIK3CA gene copy number analysis}

To assess the presence of PIK3CA gene amplifications, fluorescent in situ hybridization (FISH) assays were performed using a PIK3CA probe that hybridizes to the band 3q26.32 with a Texas Red tag (red) and centromere3 (CEN3) with a FITC tag (green) (Abbott Molecular, Abbott Park, IL), according to routine methods. At least 60 nuclei were evaluated per sample. Twenty contiguous tumor cell nuclei were analyzed from three representative foci. PIK3CA amplification was defined based on previous studies [22, 23, 25, 39]. $P I K 3 C A$ amplification was defined as if one of the following criteria is fulfilled: (1) $P I K 3 C A / C E N 3$ ratio was $\geq 2.0$ or (2) the average $P I K 3 C A$ signal per nucleus $>4.0$. Polysomy was defined as an average PIK3CA signal per nucleus $4.0 \geq$ to $>2.0$.

\section{PIK3CA mutational analysis}

Genomic DNA was extracted from 125 formalinfixed paraffin-embedded (FFPE) tissue specimens using a QIAamp DNA FFPE Tissue Kit (Qiagen, Hilden, Germany), according to the manufacturer's instructions. We used a pyrosequencing assay covering the mutational hotspots of interest to sequence exons 9 and 20 of PIK3CA [40]. The exon 9 polymerase chain reaction (PCR) primers were $\mathrm{PIK} 3 \mathrm{CA}$ 9-F, 5'-biotinAACAGCTCAAAGCAATTTCTACACG-3', and PIK3CA 9-R, 5'-ACCTGTGACTCCATAGAAAATC TTT-3'. The exon 20 PCR primers were PIK3CA 20-F, 5'-biotin-CAAGAGGCTTTGGAGTATTTCA-3', and PIK3CA 20-R, 5'-CAATCCATTTTTGTTGTCCA-3'. Each PCR mix contained the forward and reverse primers (10 $\mu \mathrm{M}$ each), $12.5 \mathrm{mM}$ dNTP mix, $3 \mathrm{mM} \mathrm{MgCl}_{2}, 1 \times$ PCR buffer, $1 \mathrm{U}$ of AmpliTaq Gold, and $100 \mathrm{ng}$ of sample genomic DNA in a total volume of $25 \mu \mathrm{L}$. PCR conditions were as follows: initial denaturation at $95^{\circ} \mathrm{C}$ for 5 minutes; 50 cycles of $94^{\circ} \mathrm{C}$ for 30 seconds, $58^{\circ} \mathrm{C}$ for 30 seconds, and $72^{\circ} \mathrm{C}$ for 40 seconds; and final extension at $72^{\circ} \mathrm{C}$ for 10 minutes. The PCR products were electrophoresed in an agarose gel to confirm successful amplification. The PCR products were sequenced using the PyroMark Q24 system (QIAGEN, Germantown, MD, USA), according to the manufacturer's instructions. Sequencing analysis was performed using PyroMark Q24 software version 1.0.10 in the allele quantification analysis mode.

\section{Statistical methods}

Associations between histologic features and clinical significance were examined using the $\chi^{2}$ test or Fisher's exact test where appropriate. Differences were statistically significant when the $P$-value was $<0.05$. Disease-free survival (DFS) was defined as the time from surgery to recurrence or last contact. Overall survival (OS) was defined as the time from surgery to death or last contact. Patients who were alive and had no recurrence at the last follow-up were censored. DFS and OS distributions were estimated using the Kaplan-Meier method. The log-rank test was used to determine survival differences between groups. Regression analyses of survival data, based on the Cox proportional hazards model, were conducted on DFS and OS. All data were analyzed using the Statistical Package for the Social Sciences Version 20.0 Software (SPSS Inc., Chicago, IL).

\section{CONFLICTS OF INTEREST}

The authors declare no conflict of interest.

\section{GRANT SUPPORT}

This study was supported by a grant from the National Research Foundation of Korea (NRF) grant funded by the Korea government (MSIP) (2015R1C1A2A01055617, Hyo Song Kim) and the R\&D Program for Society of the National Research Foundation (NRF) funded by the Ministry of Science, ICT \& Future Planning (Grant number: 2013M3C8A1078501, Jae Seok Lee). 


\section{REFERENCES}

1. Dodd LG. Update on liposarcoma: a review for cytopathologists. Diagn Cytopathol. 2012; 40:1122-1131.

2. Toro JR, Travis LB, Wu HJ, Zhu K, Fletcher CD, Devesa SS. Incidence patterns of soft tissue sarcomas, regardless of primary site, in the surveillance, epidemiology and end results program, 1978-2001: An analysis of 26,758 cases. Int J Cancer. 2006; 119:2922-2930.

3. Hoffman A, Lazar AJ, Pollock RE, Lev D. New frontiers in the treatment of liposarcoma, a therapeutically resistant malignant cohort. Drug Resist Updat. 2011; 14:52-66.

4. Fletcher CDM UK, Mertens F. (2002). Pathology \& genetics, tumoursof soft tissue and bone. IARC Press).

5. Cantley LC. The phosphoinositide 3-kinase pathway. Science. 2002; 296:1655-1657.

6. Wu G, Xing M, Mambo E, Huang X, Liu J, Guo Z, Chatterjee A, Goldenberg D, Gollin SM, Sukumar S, Trink B, Sidransky D. Somatic mutation and gain of copy number of PIK3CA in human breast cancer. Breast Cancer Res. 2005; 7:R609-616.

7. Jehan Z, Bavi P, Sultana M, Abubaker J, Bu R, Hussain A, Alsbeih G, Al-Sanea N, Abduljabbar A, Ashari LH, Alhomoud S, Al-Dayel F, Uddin S, et al. Frequent PIK3CA gene amplification and its clinical significance in colorectal cancer. J Pathol. 2009; 219:337-346.

8. Angulo B, Suarez-Gauthier A, Lopez-Rios F, Medina PP, Conde E, Tang M, Soler G, Lopez-Encuentra A, Cigudosa JC, Sanchez-Cespedes M. Expression signatures in lung cancer reveal a profile for EGFR-mutant tumours and identify selective PIK3CA overexpression by gene amplification. J Pathol. 2008; 214:347-356.

9. Bachman KE, Argani P, Samuels Y, Silliman N, Ptak J, Szabo S, Konishi H, Karakas B, Blair BG, Lin C, Peters BA, Velculescu VE, Park BH. The PIK3CA gene is mutated with high frequency in human breast cancers. Cancer Biol Ther. 2004; 3:772-775.

10. Samuels Y, Velculescu VE. Oncogenic mutations of PIK3CA in human cancers. Cell Cycle. 2004; 3:1221-1224.

11. Barretina J, Taylor BS, Banerji S, Ramos AH, LagosQuintana M, Decarolis PL, Shah K, Socci ND, Weir BA, Ho A, Chiang DY, Reva B, Mermel CH, et al. Subtypespecific genomic alterations define new targets for softtissue sarcoma therapy. Nat Genet. 2010; 42:715-721.

12. Demicco EG, Torres KE, Ghadimi MP, Colombo C, Bolshakov S, Hoffman A, Peng T, Bovee JV, Wang WL, Lev D, Lazar AJ. Involvement of the PI3K/Akt pathway in myxoid/round cell liposarcoma. Mod Pathol. 2012; 25:212-221.

13. Dalal KM, Kattan MW, Antonescu CR, Brennan MF, Singer S. Subtype specific prognostic nomogram for patients with primary liposarcoma of the retroperitoneum, extremity, or trunk. Ann Surg. 2006; 244:381-391.
14. Fiore M, Grosso F, Lo Vullo S, Pennacchioli E, Stacchiotti S, Ferrari A, Collini P, Lozza L, Mariani L, Casali PG, Gronchi A. Myxoid/round cell and pleomorphic liposarcomas: prognostic factors and survival in a series of patients treated at a single institution. Cancer. 2007; 109:2522-2531.

15. Asano N, Susa M, Hosaka S, Nakayama R, Kobayashi E, Takeuchi K, Horiuchi K, Suzuki Y, Anazawa U, Mukai M, Toyama Y, Yabe H, Morioka H. Metastatic patterns of myxoid/round cell liposarcoma: a review of a 25-year experience. Sarcoma. 2012; 2012:345161.

16. Kim HS, Lee J, Yi SY, Jun HJ, Choi YL, Ahn GH, Seo SW, Lim do H, Ahn YC, Park JO, Kim SJ. Liposarcoma: exploration of clinical prognostic factors for risk based stratification of therapy. BMC Cancer. 2009; 9:205.

17. Judson I, Verweij J, Gelderblom H, Hartmann JT, Schoffski P, Blay JY, Kerst JM, Sufliarsky J, Whelan J, Hohenberger P, Krarup-Hansen A, Alcindor T, Marreaud S, et al. Doxorubicin alone versus intensified doxorubicin plus ifosfamide for first-line treatment of advanced or metastatic soft-tissue sarcoma: a randomised controlled phase 3 trial. Lancet Oncol. 2014; 15:415-423.

18. Suda T, Hama T, Kondo S, Yuza Y, Yoshikawa M, Urashima $M$, Kato $T$, Moriyama H. Copy number amplification of the PIK3CA gene is associated with poor prognosis in non-lymph node metastatic head and neck squamous cell carcinoma. BMC Cancer. 2012; 12:416.

19. Kolasa IK, Rembiszewska A, Felisiak A, ZiolkowskaSeta I, Murawska M, Moes J, Timorek A, DansonkaMieszkowska A, Kupryjanczyk J. PIK3CA amplification associates with resistance to chemotherapy in ovarian cancer patients. Cancer Biol Ther. 2009; 8:21-26.

20. Kawano O, Sasaki H, Okuda K, Yukiue H, Yokoyama T, Yano M, Fujii Y. PIK3CA gene amplification in Japanese non-small cell lung cancer. Lung Cancer. 2007; 58:159-160.

21. Fendri A, Khabir A, Mnejja W, Sellami-Boudawara T, Daoud J, Frikha M, Ghorbel A, Gargouri A, MokdadGargouri R. PIK3CA amplification is predictive of poor prognosis in Tunisian patients with nasopharyngeal carcinoma. Cancer Sci. 2009; 100:2034-2039.

22. Massion PP, Kuo WL, Stokoe D, Olshen AB, Treseler PA, Chin K, Chen C, Polikoff D, Jain AN, Pinkel D, Albertson DG, Jablons DM, Gray JW. Genomic copy number analysis of non-small cell lung cancer using array comparative genomic hybridization: implications of the phosphatidylinositol 3-kinase pathway. Cancer Res. 2002; 62:3636-3640.

23. Woenckhaus J, Steger K, Werner E, Fenic I, Gamerdinger U, Dreyer T, Stahl U. Genomic gain of PIK3CA and increased expression of p110alpha are associated with progression of dysplasia into invasive squamous cell carcinoma. J Pathol. 2002; 198:335-342.

24. Chiosea SI, Grandis JR, Lui VW, Diergaarde B, Maxwell JH, Ferris RL, Kim SW, Luvison A, Miller M, Nikiforova 
MN. PIK3CA, HRAS and PTEN in human papillomavirus positive oropharyngeal squamous cell carcinoma. BMC Cancer. 2013; 13:602.

25. Hou P, Liu D, Shan Y, Hu S, Studeman K, Condouris S, Wang Y, Trink A, El-Naggar AK, Tallini G, Vasko V, Xing M. Genetic alterations and their relationship in the phosphatidylinositol 3-kinase/Akt pathway in thyroid cancer. Clin Cancer Res. 2007; 13:1161-1170.

26. Saal LH, Holm K, Maurer M, Memeo L, Su T, Wang X, Yu JS, Malmstrom PO, Mansukhani M, Enoksson J, Hibshoosh H, Borg A, Parsons R. PIK3CA mutations correlate with hormone receptors, node metastasis, and ERBB2, and are mutually exclusive with PTEN loss in human breast carcinoma. Cancer Res. 2005; 65:2554-2559.

27. Italiano A, Chen CL, Thomas R, Breen M, Bonnet F, Sevenet N, Longy M, Maki RG, Coindre JM, Antonescu CR. Alterations of the p53 and PIK $3 \mathrm{CA} / \mathrm{AKT} / \mathrm{mTOR}$ pathways in angiosarcomas: a pattern distinct from other sarcomas with complex genomics. Cancer. 2012; 118:5878-5887.

28. Hou J, Jiang D, Zhang J, Gavine PR, Xu S, Liu Y, Xu C, Huang J, Tan Y, Wang H, Lu Y, Zheng L, Hou Y, et al. Frequency, characterization, and prognostic analysis of PIK3CA gene mutations in Chinese esophageal squamous cell carcinoma. Hum Pathol. 2014; 45:352-358.

29. Maeng $\mathrm{CH}$, Lee J, van Hummelen P, Park SH, Palescandolo E, Jang J, Park HY, Kang SY, MacConaill L, Kim KM, Shim YM. High-throughput genotyping in metastatic esophageal squamous cell carcinoma identifies phosphoinositide-3-kinase and BRAF mutations. PLoS One. 2012; 7:e41655.

30. Maki RG, Wathen JK, Patel SR, Priebat DA, Okuno SH, Samuels B, Fanucchi M, Harmon DC, Schuetze SM, Reinke D, Thall PF, Benjamin RS, Baker LH, et al. Randomized phase II study of gemcitabine and docetaxel compared with gemcitabine alone in patients with metastatic soft tissue sarcomas: results of sarcoma alliance for research through collaboration study 002 [corrected]. J Clin Oncol. 2007; 25:2755-2763.

31. van der Graaf WT, Blay JY, Chawla SP, Kim DW, BuiNguyen B, Casali PG, Schoffski P, Aglietta M, Staddon AP, Beppu Y, Le Cesne A, Gelderblom H, Judson IR, et al. Pazopanib for metastatic soft-tissue sarcoma (PALETTE): a randomised, double-blind, placebo-controlled phase 3 trial. Lancet. 2012; 379:1879-1886.
32. Sleijfer S, Ray-Coquard I, Papai Z, Le Cesne A, Scurr M, Schoffski P, Collin F, Pandite L, Marreaud S, De Brauwer A, van Glabbeke M, Verweij J, Blay JY. Pazopanib, a multikinase angiogenesis inhibitor, in patients with relapsed or refractory advanced soft tissue sarcoma: a phase II study from the European organisation for research and treatment of cancer-soft tissue and bone sarcoma group (EORTC study 62043). J Clin Oncol. 2009; 27:3126-3132.

33. Yoo KH, Kim HS, Lee SJ, Park SH, Kim SJ, Kim SH, La Choi Y, Shin KH, Cho YJ, Lee J, Rha SY. Efficacy of pazopanib monotherapy in patients who had been heavily pretreated for metastatic soft tissue sarcoma: a retrospective case series. BMC Cancer. 2015; 15:154.

34. Dei Tos AP, Doglioni C, Piccinin S, Sciot R, Furlanetto A, Boiocchi M, Dal Cin P, Maestro R, Fletcher CD, Tallini G. Coordinated expression and amplification of the MDM2, CDK4, and HMGI-C genes in atypical lipomatous tumours. J Pathol. 2000; 190:531-536.

35. Spoerke JM, O'Brien C, Huw L, Koeppen H, Fridlyand J, Brachmann RK, Haverty PM, Pandita A, Mohan S, Sampath D, Friedman LS, Ross L, Hampton GM, et al. Phosphoinositide 3-kinase (PI3K) pathway alterations are associated with histologic subtypes and are predictive of sensitivity to PI3K inhibitors in lung cancer preclinical models. Clin Cancer Res. 2012; 18:6771-6783.

36. Fritsch C, Huang A, Chatenay-Rivauday C, Schnell C, Reddy A, Liu M, Kauffmann A, Guthy D, Erdmann D, De Pover A, Furet P, Gao H, Ferretti S, et al. Characterization of the novel and specific PI3Kalpha inhibitor NVP-BYL719 and development of the patient stratification strategy for clinical trials. Mol Cancer Ther. 2014; 13:1117-1129.

37. Sarker D, Ang JE, Baird R, Kristeleit R, Shah K, Moreno V, Clarke PA, Raynaud FI, Levy G, Ware JA, Mazina K, Lin R, Wu J, et al. First-in-human phase I study of pictilisib (GDC-0941), a potent pan-class I phosphatidylinositol-3kinase (PI3K) inhibitor, in patients with advanced solid tumors. Clin Cancer Res. 2015; 21:77-86.

38. Evans HL. Liposarcoma: a study of 55 cases with a reassessment of its classification. Am J Surg Pathol. 1979; 3:507-523.

39. Zhao L, Vogt PK. Class I PI3K in oncogenic cellular transformation. Oncogene. 2008; 27:5486-5496.

40. Nosho K, Kawasaki T, Longtine JA, Fuchs CS, Ohnishi M, Suemoto Y, Kirkner GJ, Zepf D, Yan L, Ogino S. PIK3CA mutation in colorectal cancer: relationship with genetic and epigenetic alterations. Neoplasia. 2008; 10:534-541. 